\title{
A VISUALIZAÇÃO DE DADOS DO DIREITO TRIBUTÁRIO
}

\author{
Rafael Sena da Conceição \\ Francisco Carlos Paletta
}

\author{
Escola de Comunicações e Artes/Universidade de São Paulo \\ rafaelsena@gmail.com
}

\section{Objetivos}

O trabalho tem como objetivo geral 0 desenvolvimento de um indicador que permita mensurar 0 grau de maturidade em visualização de dados do direito tributário pátrio nos municípios e também realizar benchmarking entre eles.

Visualização de dados no contexto deste trabalho deve ser entendida como a compreensibilidade das informações por um cidadão não especialista no tema.

Os objetivos específicos são: i) definir a visualização de dados no contexto do direito tributário, ii) elaborar indicador quantitativo da maturidade em visualização de dados do direito tributário nos municípios brasileiros; e iii) realizar diagnóstico do quadro atual de maturidade e elencar eventuais melhorias a partir do cômputo do indicador proposto em um conjunto de municípios.

\section{Métodos e Procedimentos}

O trabalho tem um caráter híbrido. Em parte, apresenta um viés de pesquisa básica ao conter revisão bibliográfica e sistematização de estudos prévios. Complementarmente, também tem um viés de pesquisa aplicada ao propor soluções que ajudem a melhorar o cenário atual de visualização dos dados do direito tributário.

A pesquisa apresentará também um perfil quali-quantitativo: foi elaborado um questionário a partir da sistematização dos estudos com a finalidade de compor um indicador que permita diagnosticar a maturidade em visualização de dados do direito tributário nos municípios. A análise deste questionário será através de métodos estatísticos primeiramente e depois por meio de elementos subjetivos. A aplicação do questionário será de caráter exploratório, porque exigirá uma pesquisa de campo perante agentes públicos que dominem o tema, a qual deverá ser viabilizada pela Lei de Acesso à Informação (LAI, Lei no 12.527/2011).

\section{Resultados}

O trabalho, devido a pandemia do COVID-19, ainda está em desenvolvimento.

O questionário foi aplicado em municípios de grande porte e que possuem significativas receitas próprias: São Paulo, Recife e Salvador. As respostas já foram recebidas. No momento, o indicador de cada um deles está sendo computado. Posteriormente, os resultados serão tabulados e analisados.

\section{Conclusões}

Numa análise preliminar e sumária dos questionários foi constatada a preocupação dos entes federados participantes com a visualização dos dados e que diversas medidas estão sendo tomadas neste sentido, tal como a adoção de padrões de redação legislativa, disponibilização de sistemas sofisticados de consultas aos bancos de dados normativos e oferecimento de recursos de acessibilidade nos portais eletrônicos.

Como cada município participante tem empreendido diferentes iniciativas, vislumbrase a possibilidade de um intercâmbio complementar e frutífero de experiências.

\section{Referências Bibliográficas}
ALVES FILHO,
organizacionais:
B. F. Processos
racionalização. São Paulo: Atlas, 2011 . 
BONIFÁCIO, R.; SCHLEGEL, R. Panorama e determinantes da satisfação com os serviços públicos no Brasil. Revista Do Serviço Público, v. 63, n. 4, p. 413-434, 2014.

BORGES, M. A. G. A compreensão da sociedade da informação. Ciência da Informação, Brasília, 29, Dezembro 2000

CHEN, J. et al. Big data challenge: a data management perspective. Frontiers of Computer Science, 7, 1 Abril 2013.

CHIAVENATO, I. Introdução à Teoria Geral da Administração. 7. ed. Rio de Janeiro: Elsevier, 2004.

CNI. Retratos da Sociedade Brasileira PRINCIPAIS PROBLEMAS DO PAÍS E PRIORIDADES PARA 2020. [s.l: s.n.]. Disponível em: <https://bucket-gw-cni-staticcms-

si.s3.amazonaws.com/media/filer_public/61/4f/6 14fa7f2-6847-45b8-ada2-

8859 ed771052/retratosdasociedadebrasileira 5 3 principaisproblemaseprioridades.pdf>

DAVIS, M. M.; AQUILINO, N. J.; CHASE, R. B. Fundamentos da administração da produção. Porto Alegre: Bookman, 2001.

FIDELIA, I.-S.; BOWKER, G. Implications of big data for knowledge organization, 2017.

GOLDONI, V.; OLIVEIRA, M. INDICADORES PARA A GESTÃO DO CONHECIMENTO NA VISÃO DE ESPECIALISTAS. Revista Eletrônica de Administração, v. 13, n. 3, p. 478-501, 2007.

GONÇALVES, F. P. F. s princípios gerais da Administração Pública e neoconstitucionalismo. In: DI PIETRO, M. S. Z. SUNDFELD, C. A. Direito Administrativo. São Paulo: Revista dos Tribunais, v. 1, 2013. Cap. 39, p. 831-851.

HELBING, D. Thinking Ahead - Essays on Big Data, Digital Revolution, and Participatory Market Society. Switzerland: Springer, 2015.

HESSE, B. W.; MOSER, R. ; RILEY, W.. From Big Data to Knowledge in the Social Sciences. The ANNALS of the American Academy of Political and Social Science, 659. 16-32. HIETALA, J.; HARJU, J.; KUOSMANEN, S Why Do We Spend All That Time Searching for Information at Work? Valamis, 2019. Disponivel em: $<$ https://www.valamis.com/blog/why-do-wespend-all-that-time-searching-for-information-atwork>. Acesso em: 07 Janeiro 2020.
LOR, P. J.; BRITZ, J. J. Is a knowledge society possible without freedom of access to information? Journal of Information Science, 33, 1 Agosto 2007. 387-397.

MARTINS, M. C. C. Ontologia legal - estudo sobre a modelagem do conhecimento legal no contexto do direito tributário. 5ำ Prêmio Schöntag. Secretaria da Receita Federal do Brasil. [S.I.]. 2006.

MERQUIOR, J. G. O Liberalismo Antigo e Moderno. 3. ed. São Paulo: É Realizações, 2014.

OLIVEIRA, J. M. D. A Relação entre Educação, Transparência, Democracia e Qualidade da Tributação. In: SANTI, E. M. D. D. Tributação e desenvolvimento homenagem ao Prof. Aires Barreto. São Paulo: [s.n.], 2011. p. 389405.

ROZADOS, H. B. F. Uso de indicadores na gestão de recursos de informação. RDBCl: Revista Digital de Biblioteconomia e Ciência da Informação, v. 3, n. 1, p. 60, 30 set. 2005. SCHOUERI, L. E. Direito tributário. 9a. ed. São Paulo: Saraiva, 2019.

SEVERIANO, R. H. GCN: Gestão do Conhecimento na Negociação. Dissertação (Metrado). Universidade Federal do Rio de Janeiro. Rio de Janeiro. 2007.

SUNDFELD, C. A. Princípios da Publicidade Administrativa - Direito de Certidão, Vista e Informação. In: DI PIETRO, M. S. Z.; SUNDFELD, C. A. Direito administrativo. São Paulo: Revista dos Tribunais, v. 1, 2013. Cap. 32, p. 691-707.

SUTTER, É. Documentation, Information, Connaissances: la gestion de la qualité. Paris: ABFF, 2002.

WILMERS, J. T. A. V. L. GESTÃO DA INFORMAÇÃO E DO CONHECIMENTO NO ÂMBITO DA INDÚSTRIA 4.0: APROXIMAÇÃO DAS TEMÁTICAS DE ESTUDO POR ANÁLISE BIBLIOMÉTRICA. Dissertação (Mestrado). Universidade Federal de São Carlos, campus de São Carlos. São Carlos. 2019 